\title{
Taxonomies of cognition
}

\section{Joan B. Silk examines Frans de Waal's treatise on the evolution of animal intelligence.}

\section{$\mathrm{I}$} n Are We Smart Enough to Know How Smart Animals Are?, ethologist Frans de ligence in nature. His is an entertaining account of how octopuses escape from jars by unscrewing the lids and rooks drop pebbles into a tube to access floating rewards. Natural selection, he argues, shapes cognitive abilities in the same way as it shapes traits such as wing length. As animals' challenges and habitats differ, so do their cognitive abilities. This idea, which he calls evolutionary cognition, has gained traction in psychology and biology in the past few decades.

For de Waal, evolutionary cognition has two key consequences. First, it is inconsistent with the concept of a 'great chain of being' in which organisms can be ordered from primitive to advanced, simple to complex, stupid to smart. Name a 'unique' human trait, and biologists will find another organism with a similar one. Humans make and use tools; so do wild New Caledonian crows (Corvus moneduloides). Humans develop cultures; so do humpback whales (Megaptera novaeangliae), which socially transmit foraging techniques. We can mentally 'time travel', remembering past events and planning for the future; so can western scrub jays (Aphelocoma californica), which can recall what they had for breakfast on one day, anticipate whether they will be given breakfast the next and selectively cache food when breakfast won't be delivered.

Furthermore, humans do not necessarily outdo other animals in all cognitive domains. Black-capped chickadees (Poecile atricapillus) store seeds in hundreds of locations each day, and can remember what they stored and where, as well as whether items in each location have been eaten, or stolen. Natural selection has favoured those prodigious feats of memory because they spell the difference between surviving winter and starving before spring. Human memory doesn't need to be as good: primates evolved in the tropics. "In the utilitarian view of biology," de Waal argues, "animals have the brains they need nothing more, nothing less."

The second consequence of de Waal's view is that there is continuity across taxa. One source of continuity is based on evolutionary history: natural selection modifies traits to create new ones, producing commonalities among species with a common history. He points out that tool use is found not just in humans and chimpanzees, but also in other apes and monkeys, Waal celebrates the evolution of intel-

implying that relevant cognitive building blocks are shared across all primates. Continuity is also generated by convergent

\author{
Are We Smart \\ Enough to Know \\ How Smart \\ Animals are? \\ FRANS DE WAAL \\ W. W. Norton: 2016
} evolution, which produces similar traits in distantly related organisms such as New Caledonian crows and capuchin monkeys. De Waal opines that continuity "ought to be the default position for at least all mammals, and perhaps also birds and other vertebrates".

$\mathrm{He}$ calls for a moratorium on claims of human uniqueness, arguing that their proponents have overvalued human complexity, or undervalued that of other species. And he is correct that such claims have been repeatedly refuted - and often have a nonscientific basis. Charles Darwin's On The Origin of Species (1859) and The Descent of Man (1871) may be 150 years behind us, but many people remain uncomfortable with the view that humans are the product of the same processes that shaped other organisms. As the Bishop of Worcester's wife reportedly exclaimed when she heard of Darwin's theory: "Dear me, let us hope it is not true. But if it is true, let us hope it does not become widely known." And some who acknowledge natural selection's role in our origins are less comfortable with the idea that it has important effects on how we think, feel and behave. Efforts to introduce evolutionary perspectives into anthropology and psychology in the 1980s met fierce resistance and remain controversial.

But anthropocentrism, or what de Waal calls "anthropodenial", is not the only reason researchers are eager to understand what is distinctly human; some are driven by curiosity about how humans came to dominate the planet. The biomass of humans and domesticated animals exceeds the biomass of all wild vertebrate species. Our success presumably has something to do with the emergence of a

\section{A woodpecker finch (Camarhynchus} pallidus) uses a stick for foraging.

176 | NATURE | VOL 532 | 14 APRIL 2016 unique suite of cognitive traits.

De Waal recognizes only one such trait: our rich and flexible system of symbolic communication, and our ability to exchange information about past and future. His commitment to the principle of continuity forces him to discount the importance of language for human cognition because of evidence of thinking by non-linguistic creatures. And he ignores compelling findings from linguists and developmental psychologists such as Elizabeth Spelke on the formative role of language in cognition.

De Waal pays little attention to the evolutionary processes that create inter-species differences. Every species is a mixture of traits inherited from ancestral taxa and derived traits that evolved after the species diverged onto its own path. So colour perception is due to visual pigments made of opsins, proteins sensitive to particular wavelengths of light. Most mammals have only two and cannot distinguish between red and green. Homo sapiens can because of the duplication and modification of an opsin gene in the common ancestor of apes and Old World monkeys, which all have three such genes. Derived traits produce real discontinuities between species.

A better book would have celebrated both similarities in the foundations of cognitive abilities across species, and processes that produce differences in cognitive abilities between species. A more useful book would have included some discussion of mechanisms (such as perception) that underlie cognitive abilities in different taxa. A more balanced book would not categorize as "killjoy accounts" all sceptical accounts of de Waal's favoured cognitively generous interpretations of behaviour, or summarily reject negative evidence from well-designed experiments. A more satisfying book would leave readers with a clearer understanding of why, a few million years after our lineage diverged from the lineage of chimpanzees, we are the ones reading this book, and not them.

Joan B. Silk is in the Institute of Human Origins at Arizona State University, Tempe. e-mail:joansilk@gmail.com

\section{CORRECTION}

In the essay 'Getting the circulation going' (Nature 531, 443-446; 2016), William

McDonough was said to have studied under John Lyle; in fact, they collaborated. 